\title{
Middle Ear Evaluation in Chronic Suppurative Otitis Media: Otomicroscopy versus Otoendoscopy-A Comparative Study
}

\author{
${ }^{1}$ Sneha Goel, ${ }^{2}$ Abhey Sood, ${ }^{3}$ Sandip M Parmar
}

\begin{abstract}
Objective: Despite continuous technical advancements, the basic optic principles and their limitations have remained the same over the past few decades. This study was aimed at visualizing and evaluating the middle ear structures with the help of otomicroscope and angled endoscopes in cases of chronic suppurative otitis media.

Materials and methods: In this prospective study, 180 patients (200 ears) above the age of 18 years with CSOM were examined by otomicroscopy and otoendoscopy. The visualizations of middle ear structures were compared and statistically analyzed.

Results: In all the parameters studied, endoscopy provided a significantly better visualization as compared to microscope. Zero degree was better than microscopy in visualization of round window niche, oval window niche and facial recess even though not statistically significant. 30 and 70 degrees provided good visualization of the round window niche, oval window niche, facial recess, sinus tympani, pyramid, stapedius tendon, long process of incus, incudostapedial joint, stapes suprastructure, eustachian tube opening, hypotympanum and fundus of retraction pockets.
\end{abstract}

Conclusion: Otoendoscopy provides better visualization of all the middle ear structures as compared to otomicroscope. Endoscopy must therefore be more frequently used in the OPD setup, so that more and more cases can be rightly diagnosed thus preventing surprises for the operating surgeon.

Keywords: Chronic suppurative otitis media, Middle ear, Otoendoscopy, Otomicroscopy

How to cite this article: Goel S, Sood A, Parmar SM. Middle Ear Evaluation in Chronic Suppurative Otitis Media: Otomicroscopy versus Otoendoscopy—A Comparative Study. Int J Otorhinolaryngol Clin 2018;10(3):87-90.

Source of support: Nil

Conflict of interest: None

\section{INTRODUCTION}

Technological innovation has led to the invention of instruments which were at first used as support to medical study. Today, these instruments have become indispensable tools in assessing clinical pattern and diagnosis. In fact, otology has been one of the most important specialties which has been benefited from such

\footnotetext{
${ }^{1}$ Junior Resident, ${ }^{2}$ Professor and Head, ${ }^{3}$ Professor

${ }^{1-3}$ Department of ENT, Muzaffarnagar Medical College, Modinagar, Uttar Pradesh, India

Corresponding Author: Sandip M Parmar, Professor, Department of ENT, Muzaffarnagar Medical College, Modinagar, Uttar Pradesh, India, e-mail: drsandip8376@gmail.com
}

technological innovations. In otology, visual inspection is the primary element in correctly formulating a diagnosis ${ }^{1}$.

Tympanic membrane is the window to middle ear, but only observing it with the naked eye is not enough to diagnose every pathology. Nowadays, otologists have a large range support at disposal, such as microscope and endoscopes. These instruments, by means of tele-cameras and photographic equipment, enable the otologists to visualize and document middle ear pathologies which is essential for their surgical treatment ${ }^{1}$. Moreover, the anatomy of the middle ear is particularly complex and an endoscopic approach represents an improvement with regard to the anatomic concepts of this region because it guarantees round-the-corner views of hidden areas².

Middle ear endoscopy is an OPD procedure that has demonstrated an important adjunctive role in the evaluation of otologic disease. The high accuracy and relatively simplicity of rigid otoendoscopy makes it very important to be used as presurgical diagnostic tool. The otoendoscopy offers a portable and a low cost tool that can pass through preexisting tympanic membrane perforation in patients with $\mathrm{CSOM}^{3}$

\section{MATERIALS AND METHODS}

This prospective study includes 180 patients (200 ears) with chronic suppurative otitis media who had presented to the ENT outpatient department of Muzaffarnagar Medical College, from October 2016 to August 2018.

Inclusion criteria: Sample includes all cases of chronic otitis media above the age of 18 years with dry ears. Retraction pockets were selected to study their detailed anatomical findings.

Exclusion criteria: All cases below 18 years of age, patients with external auditory canal pathologies where passing a scope can be difficult anatomically or painful to the patient.

A detailed history and ENT examination was done followed by otoscopic examination. A written informed consent was taken prior to examination. The patient was placed in supine position. After cleaning his/her ear, a proper otomicroscopic evaluation was carried out. A Carl Zeiss Opmi Pico Microscope $250 \mathrm{~mm}$ lens was used in the study. Tian Song ( $2.7 \mathrm{~mm}$ or $4 \mathrm{~mm}$ diameter, $175 \mathrm{~mm}$ length) 0 -, 30- and 70-degree rigid nasal endoscopes attached to an external light source were used. 
The middle ear structures assessed were the middle ear mucosa, medial wall of the middle ear (round and oval window area ), auditory ossicles (malleus, incus, stapes), eustachian tube, retraction pockets and blind niches (sinus tympani, facial recess, attic, hypotympanum). The percentage of cases of visualization using both techniques were calculated and subjected to statistical analysis.

\section{RESULTS}

In this prospective study, 180 patients (200 ears) with CSOM were studied, among which 36 were of the squamosal type and the 164 were of the mucosal type (Table 1$)$.

Middle ear structures which were better evaluated with both 30- and 70-degree endoscopes (statistically highly significant) than microscope are round window niche, oval window niche, facial recess, sinus tympani, pyramid, stapedius tendon, incudostapedial joint, stapes suprastructure, eustachian tube opening, hypotympanum.

Middle ear structures which were better evaluated with both 30- and 70-degree endoscopes (statistically significant) than microscope are long process of incus.

Middle ear structure which was better evaluated with 30-degree endoscope (statistically highly significant) than microscope is fundus of retraction pocket.

Middle ear structures which were better evaluated with 0 degree endoscopes (statistically significant) than microscope are round window niche, oval window niche and Facial recess.

Middle ear structures which were better evaluated with 70-degree endoscopes (statistically significant) than microscope is fundus of retraction pocket.

Zero degree was better than microscopy in these parameters even though not statistically significant are pyramid, stapedius tendon, long process of incus, incudostapedial joint, stapes suprastructure, eustacian tube opening, hypotympanum and fundus of retraction pocket.

\section{DISCUSSION}

In this prospective study, 200 ears of chronic suppurative otitis media were studied among which 36 were of the squamosal type and the rest 164 were of the mucosal type (Table 1).

Evaluation of middle ear mucosa in this study, showed no statistically significant advantage of endoscopes over the microscope though appreciation was better with endoscopes.

Round window niche visualisation showed statistical significance advantage with zero degree endoscope ( $p$ value 0.040 ), while both 30 and 70 degree endoscope on comparing with microscope showed high statistical significance ( $p$ value $<0.0001$ ) (Table $2 \mathrm{~A}$ ). Klug et $\mathrm{al}^{4}$ and Livi et $\mathrm{al}^{1}$ had studied that the round window niche is better visualized with the wider angle of the 30 degree endoscope.

Oval window area visualization with zero degree endoscope showed statistical significance ( $p$ value 0.003 ), while both 30 and 70 degree endoscope on comparing with microscope showed high statistical significance ( $p$ value $<0.001$ ) (Table 2A). A similar study by Shehzad Ghaffar et $\mathrm{al}^{5}$ has mentioned that the medial wall of middle ear is best viewed with the 30 degree endoscope.

Facial recess visualisation with zero degree endoscope showed statistical significance ( $p$ value 0.751$)$, while both 30 and 70-degree endoscope on comparing with microscope showed high statistical significance ( $p$ value $<0.001$ ) (Table 2B). Walter Livi et $\mathrm{al}^{1}$, Tarabichi $\mathrm{M}^{6}$ had found that the facial recess is best viewed by the 70 degree endoscope.

Sinus tympani, Stapedius tendon and Pyramid visualization with 30 and 70 degree endoscope on comparing with microscope showed high statistical significance ( $p$ value $<0.001$ ) (Table 2B). According to Klug et al ${ }^{4}$ Sinus tympani is better viewed with a 30 degree endoscope and Berretini S, Neri E et $\mathrm{al}^{7}$ stated that the stapedius tendon could be visualized by means of rigid endoscopy than with virtual endoscopy.

Visualisation of Handle of malleus showed no statistical significance with the 0,30 and 70 degree endoscope. Long process of incus showed statistical significance ( $p$ value 0.0003 ) with 30 and 70 degree endoscope on comparing with microscope. Stapes suprastructure and Incudostapedial joint visualisation also showed high

Table 1: Distribution of central perforations in pars tensa according to their size and retraction pockets in all the CSOM cases evaluated

\begin{tabular}{|c|c|c|c|c|c|c|c|c|}
\hline \multirow[t]{2}{*}{ Size } & \multirow[t]{2}{*}{ Mucosal } & \multirow[t]{2}{*}{$\% *$} & \multicolumn{4}{|c|}{ Squamosal } & \multirow[t]{2}{*}{ Total } & \multirow[t]{2}{*}{$\%^{*}$} \\
\hline & & & Inactive & $\%^{*}$ & Active & $\%^{*}$ & & \\
\hline Small & 24 & 92.3 & 2 (marginal) & 7.7 & 0 & 0 & 26 & 13 \\
\hline Moderate & 62 & 100 & 0 & 0 & 0 & 0 & 62 & 31 \\
\hline Large & 78 & 100 & 0 & 0 & 0 & 0 & 78 & 39 \\
\hline Retraction pockets & 0 & 0 & 10 & 29.4 & 24 & 70.6 & 34 & 17 \\
\hline Total & 164 & 82 & 12 & 6 & 24 & 12 & 200 & 100 \\
\hline
\end{tabular}

${ }^{*}$ Percentage calculated for Rows 
Table 2A: Visualization of some middle ear structures with otomicroscope and otoendoscope

\begin{tabular}{|c|c|c|c|c|c|c|c|c|}
\hline \multirow{2}{*}{$\begin{array}{l}\text { Middle ear } \\
\text { structure }\end{array}$} & \multicolumn{2}{|c|}{ Microscope } & \multicolumn{2}{|c|}{ Endoscope $0^{0}$} & \multicolumn{2}{|c|}{ Endoscope $30^{\circ}$} & \multicolumn{2}{|c|}{ Endoscope $70^{\circ}$} \\
\hline & No. & $\%$ & No. & $\%$ & No. & $\%$ & No. & $\%$ \\
\hline \multicolumn{9}{|l|}{ Round window } \\
\hline Not visualized & 126 & 63 & 116 & 58 & 82 & 41 & 90 & 45 \\
\hline $\begin{array}{l}\text { Fully } \\
\text { visualized }\end{array}$ & 6 & 3 & 18 & 9 & 66 & 33 & 58 & 29 \\
\hline \multirow{2}{*}{$\begin{array}{l}\text { Partially } \\
\text { visualized }\end{array}$} & 68 & 34 & 66 & 33 & 52 & 26 & 52 & 26 \\
\hline & & & \multicolumn{2}{|c|}{$p 0.040$ (S) } & \multicolumn{2}{|c|}{$p<0.0001(\mathrm{HS})$} & \multicolumn{2}{|c|}{$p<0.0001(\mathrm{HS})$} \\
\hline \multicolumn{9}{|l|}{ Oval window } \\
\hline Not visualized & 152 & 76 & 144 & 72 & 102 & 51 & 90 & 45 \\
\hline $\begin{array}{l}\text { Fully } \\
\text { visualized }\end{array}$ & 4 & 2 & 20 & 10 & 42 & 21 & 46 & 23 \\
\hline \multirow{2}{*}{$\begin{array}{l}\text { Partially } \\
\text { visualized }\end{array}$} & 44 & 22 & 36 & 18 & 56 & 28 & 64 & 32 \\
\hline & & & \multicolumn{2}{|c|}{$p 0.003$ (S) } & \multicolumn{2}{|c|}{$p<0.0001(\mathrm{HS})$} & \multicolumn{2}{|c|}{$p<0.0001(\mathrm{HS})$} \\
\hline
\end{tabular}

Table 2B: Visualization of some middle ear structures with otomicroscope and otoendoscope

\begin{tabular}{|c|c|c|c|c|c|c|c|c|}
\hline \multirow{2}{*}{$\begin{array}{l}\text { Middle Ear } \\
\text { Structure }\end{array}$} & \multicolumn{2}{|c|}{ Microscope } & \multicolumn{2}{|c|}{ Endoscope $0^{0}$} & \multicolumn{2}{|c|}{ Endoscope $30^{\circ}$} & \multicolumn{2}{|c|}{ Endoscope $70^{\circ}$} \\
\hline & No. & $\%$ & No. & $\%$ & No. & $\%$ & No. & $\%$ \\
\hline \multicolumn{9}{|l|}{ Facial recess } \\
\hline Not visualized & 196 & 98 & 194 & 97 & 144 & 72 & 142 & 71 \\
\hline \multirow[t]{2}{*}{ Visualized } & 4 & 2 & 6 & 3 & 56 & 28 & 58 & 29 \\
\hline & & & \multicolumn{2}{|c|}{$p 0.751(\mathrm{~S})$} & \multicolumn{2}{|c|}{$p<0.0001(\mathrm{HS})$} & \multicolumn{2}{|c|}{$p<0.0001(\mathrm{HS})$} \\
\hline \multicolumn{9}{|c|}{ Eustachian tube opening } \\
\hline Not visualized & 152 & 76 & 143 & 71.5 & 110 & 55 & 115 & 57.5 \\
\hline Fully visualized & 6 & 3 & 9 & 4.5 & 72 & 36 & 67 & 33.5 \\
\hline \multirow[t]{2}{*}{ Partially visualized } & 42 & 21 & 48 & 24 & 18 & 9 & 18 & 9 \\
\hline & & & \multicolumn{2}{|c|}{$p 0.529$ (NS) } & \multicolumn{2}{|c|}{$p<0.0001(\mathrm{HS})$} & \multicolumn{2}{|c|}{$p<0.0001(\mathrm{HS})$} \\
\hline \multicolumn{9}{|l|}{ Sinus tympani } \\
\hline Not visualized & 200 & 100 & 200 & 100 & 156 & 78 & 151 & 75.5 \\
\hline \multirow[t]{2}{*}{ Visualized } & 0 & 0 & 0 & 0 & 44 & 22 & 49 & 24.5 \\
\hline & & & \multicolumn{2}{|l|}{$p(-)$} & \multicolumn{2}{|c|}{$p<0.0001(\mathrm{HS})$} & \multicolumn{2}{|c|}{$p<0.0001(\mathrm{HS})$} \\
\hline
\end{tabular}

statistical significance ( $p$ value $<0.001$ ) with 30 and 70 degree endoscopy compared to microscopy. Toth $\mathrm{M} \mathrm{et} \mathrm{al}^{8}$ detailed anatomic description of the auditory ossicles in his study with 0 and 30-degree endoscopes concluding better evaluation compared to microscope.

Visualization of eustachian tube opening and hypotympanum with microscope and 0 degree endoscope showed no statistical significance, while both $30-$ and 70-degree endoscopy showed high statistical significance ( $p$ value $<0.0001$ ) (Table 2B) (Figure 1). Klug et $\mathrm{al}^{4}$ and Karhuketo et al. ${ }^{9}$ had described that the tympanic orifice of the tube can be seen better with a 70-degree endoscope. Livi et al. ${ }^{1}$ and Klug et al. ${ }^{4}$ described that the hypotympanum can be best visualized with a 70-degree endoscope.

Visualization of the Fundus of the retraction pocket with 30-degree endoscopy showed high statistical significance on comparison with microscopy ( $p$ value $<$ 0.001 ). With 70-degree endoscope showed statistical significance ( $p$ value 0.0005$)$. Drew M Horlbeck ${ }^{10}$ mentioned that the use of endoscope has been extended beyond its use as a tool for diagnosing middle ear disease.

\section{CONCLUSION}

It was concluded from this study that endoscopy is very effective for viewing the obscure sites of the middle ear as compared to microscopy. In all the parameters studied, endoscopy provided a significantly better visualization with regards to microscope.

\section{CLINICAL SIGNIFICANCE}

Endoscopy should be more frequently used in the OPD set up, so that more and more cases can be rightly 

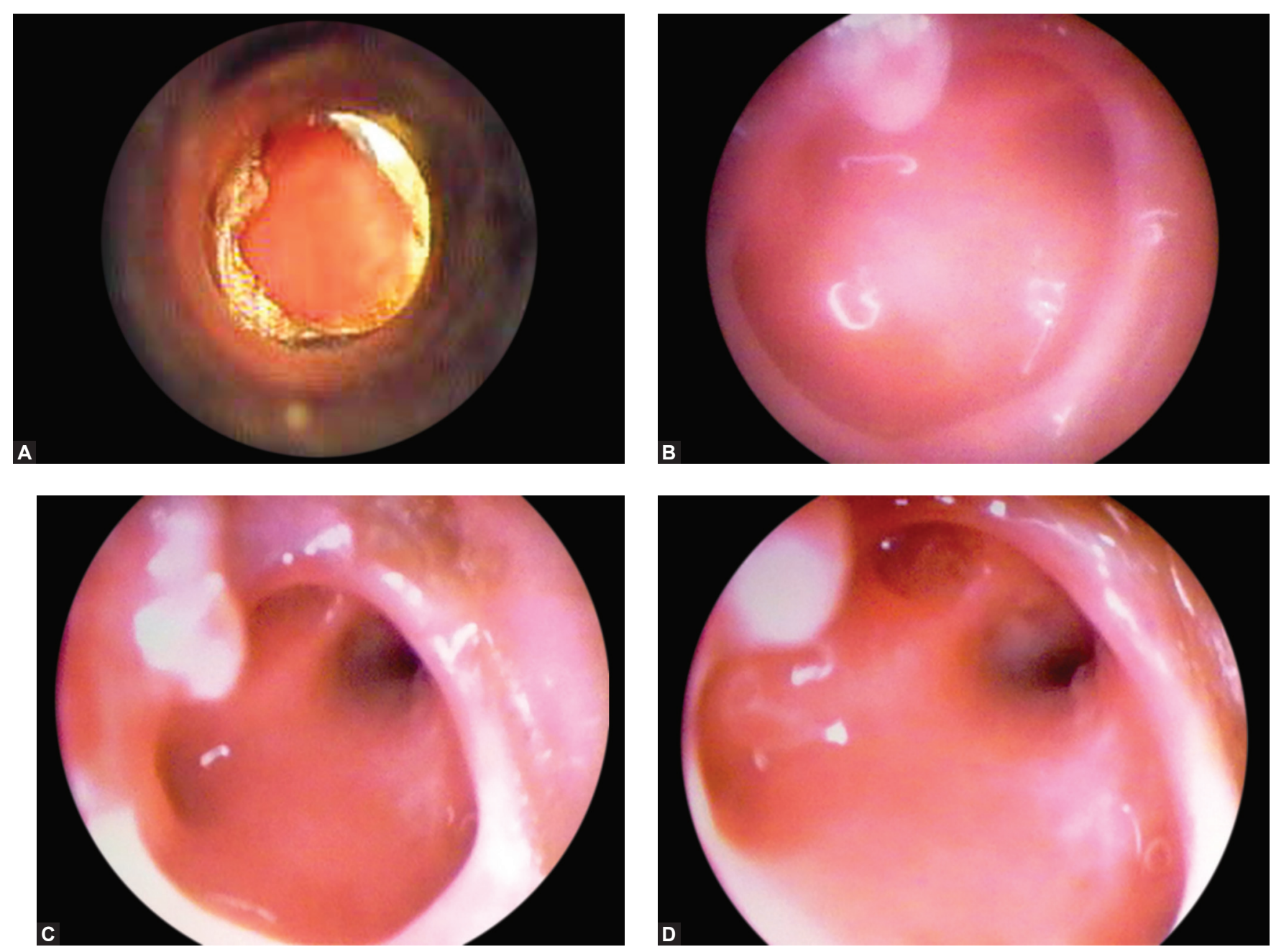

Figs 1A to D: A case of right CSOM (mucosal) with large size central perforation evaluated with microscope, 0-, 30-, and 70-degree endoscopes. (A) No middle ear structure seen on microscopy except for the middle ear mucosa; (B) On 0-degree endoscopy ETO, RWN, OWA and tip of HOM partially; (C) On 30-degree endoscopy, ETO is fully visualized, RWN and OW area also visualized; (D) On 70-degree endoscopy, lumen of the ET is visualized. ETO, eustachian tube orifice; RWN, round window niche; OWA, oval window area.

diagnosed thus preventing surprises for the operating surgeon.

\section{REFERENCES}

1. Walter Livi, Elisabetta Franci Endoscopes in surgery for otitis media, Atlas of otitis media Clinicopathologic correlations and operative techniques 2005; 17:139-147

2. Marchioni D, Alicandri-Ciufelli M, Piccinini A, et al. Inferior retrotympanum revisited: an endoscopic anatomic study. Laryngoscope. 2010;120:1880-1886. [PubMed]

3. Yaseen ET, Abdullah AH, Jwery AK, et al. Otoendoscopic evaluation of the middle ear hidden areas in chronic suppurative otitis media. J Otolaryngol ENT Res. 2018;10(3):176-178. DOI:10.15406/joentr.2018.10.00340

4. Klug C, Tschabitscher M. Two-Port Endoscopy of the middle ear Endoscopic anatomy. Arch Otolaryngol Head Neck Surg. Vol 125, Apr 1999:433-437.
5. Shehzad Ghaffar "Incorporating the endoscope into middle ear surgery". Ear, Nose \& Throat Journal. FindArticles. com. 2006. http://findarticles.com/p/articles/mi_m0BUM/ is_9_85/ai_n16807265.

6. Tarabichi M, Endoscopic middle ear surgery, Ann OtolRhinol Laryngol 1999;108:39-46.

7. Berrettini S, Neri E, Ravecea F, Forli F, Correlations between virtual endoscopy and otoendoscopy of the retrotympanum, Arch Otolaryngol. July 2002; 122(5):474-478.

8. Toth M, Nagy K, Patonay L, Endoscopic anatomy of the tympanic cavity, Orv Hetil 1998;139:169-496.

9. Karhuketu TS, Laippala PJ, Puhakka HJ, Sipila MM. Endoscopy \& Otomicroscopy in estimation of middle ear structures. Acta Otolaryngology (Stockh) 1997; 117:585-589.

10. Drew M Horlbeck, e Medicine, Medscapes continually updated clinical reference 2006, http://emedicine.medscape. com /article / 860570-media. 